\title{
Academia and Industry Partnership: Building State-of-the-Art Industrial Control and Automation Laboratory
}

\section{Prof. Aleksandr Sergeyev, Michigan Technological University}

Aleksandr Sergeyev is currently an Associate Professor in the Electrical Engineering Technology program in the School of Technology at Michigan Technological University. Dr. Aleksandr Sergeyev earned his bachelor degree in Electrical Engineering at Moscow University of Electronics and Automation in 1995. He obtained the Master degree in Physics from Michigan Technological University in 2004 and the $\mathrm{PhD}$ degree in Electrical Engineering from Michigan Technological University in 2007. Dr. Aleksandr Sergeyev's research interests include high energy laser propagation through the turbulent atmosphere, developing advanced control algorithms for wavefront sensing and mitigating effects of the turbulent atmosphere, digital inline holography, digital signal processing, and laser spectroscopy. Dr. Sergeyev is a member of ASEE, IEEE, SPIE and is actively involved in promoting engineering education.

\section{Dr. Nasser Alaraje, Michigan Technological University}

Dr. Alaraje is an Associate Professor and Program Chair of Electrical Engineering Technology in the School of Technology at Michigan Tech. Prior to his faculty appointment, he was employed by Lucent Technologies as a hardware design engineer, from 1997- 2002, and by vLogix as chief hardware design engineer, from 2002-2004. In 2009, Alaraje was awarded the Golden Jubilee by the College of Engineering at Assiut University, in Egypt. He has served as an ABET/IEEE-TAC evaluator for electrical engineering technology and computer engineering technology programs. Dr. Alaraje is a 2013-2014 Fulbright scholarship recipient at Qatar University, where he taught courses on Embedded Systems. Additionally, Dr. Alaraje is recipient of an NSF award for a digital logic design curriculum revision in collaboration with College of Lake County in Illinois, and NSF award in collaboration with University of New Mexico, Drake State Technical College and Chandler-Gilbert Community College, the award is focusing on expanding outreach activities to increase the awareness of potential college students about career opportunities in electronics technologies.

\section{Dr. James O. Frendewey, Michigan Technological University \\ Dr. Mohsen Azizi, Michigan Technological University}

M. Azizi received the Ph.D. degree in electrical and computer engineering from Concordia University, Montreal, Canada, in 2010. From 2010 to 2013, he was a R\&D engineer at Pratt \& Whitney Canada Inc. and Aviya Tech Inc., Longueuil, Canada. Since 2012 he has been an adjunct assistant professor in electrical and computer engineering at Concordia University. In 2013 he joined Michigan Technological University, Houghton, Michigan, where he is currently an assistant professor in electrical engineering technology. His research interests include cooperative control and networked estimation in multi-agent systems, distributed and decentralized control of large-scale systems, and fault diagnosis, isolation and recovery (FDIR). He is specifically interested in the application of control systems and diagnostics in jet engines, unmanned vehicles, aircraft, and power systems.

Dr. Azizi was the recipient of the Natural Sciences and Engineering Research Council of Canada (NSERC) Postgraduate Scholarship Doctoral 2007-2010, and Fonds québécois de la recherche sur la nature et les technologies (FQRNT) Postdoctoral Fellowship from the Government of Quebec 2011-2012. 


\title{
Academia and Industry Partnership: Building State-of-the-Art Industrial Control and Automation Laboratory
}

\begin{abstract}
Programmable Logical Controller (PLC) is an integral part of nearly all today's industrial processes. A PLC is a digital computer used for automation of electromechanical processes and is designed for multiple inputs and output arrangements, extended temperature ranges, immunity to electrical noise, and resistance to vibration and impact. The most up-to-date PLCs have endless functionality, including programming using functional blocks, multitasking, and communication capabilities, and therefore are widely employed by the industrial sector. It is also very common that PLC systems are integrated with robotic solutions to enhance automation processes. As a result, the skills of newly employed industrial workers must include the knowledge of PLC, controls, and robotics. In addition, the knowledge of integration of all these tools in one efficient automated process suiting the requirements of modern industrial environment is crucial.
\end{abstract}

Michigan Technological University prepares the graduates with the skill sets which are up-todate and relevant to the modern technologies widely employed by the modern industrial world. We strive to train our graduates on the most up-to-date laboratory equipment so they can implement their knowledge on the day one once employed. Michigan Tech collaborates with NUCOR Steel to update the currently outdated PLC laboratory with the state of the art equipment with the goal of providing our students with the best training solution possible. The EET program at Michigan Tech currently offers two PLC courses: EET 3373 Introduction to Programmable Controllers and EET 4373 Advanced Programmable Controllers. The ECE department offers EE3261 Control Systems and EE 4262 Digital and Non-linear Control. The EET courses have a significant lab component and stress hands-on use of PLC's, while ECE courses have more of a mathematical flavor and also include a lab experience. The new lab facility would allow EET 3373 and EET 4373 to be revised and enhanced to make the courses appropriate for both ECE and EET students. Students from both disciplines would benefit from using the most current PLC technology and would have the opportunity to interface the PLC's with a new and much expanded set of digital and analog devices that are used in industry. In addition, the new equipment will allow us to develop industry-relevant learning materials, and provide state-of the-art knowledge and experience to students utilizing the facility. This knowledge and experience will result in a well-educated graduate with practical hands-on experience designing, configuring, and troubleshooting industrial control systems, with an obvious benefit to employers of these graduates.

In this article we discuss the benefits of academia and industry collaboration, the structure of new industrial control and automation laboratory, state-of-the art PLC and Mechatronics stations integrated with FANUC robots, and resulting curriculum modifications.

\section{Introduction}


In 2014, ManpowerGroup surveyed nearly 40,000 employers across 41 countries and territories as part of its annual Talent Shortage Survey ${ }^{1}$ and identified that employers are having the most difficulty finding the right people to fill jobs in Japan $81 \%$, Brazil $63 \%$ and the US $40 \%$. In fact, two occupations in the US: technicians (primarily production/operations, engineering or mathematics) and engineers top the list of 10 jobs employers have difficulty filling. In addition, the American Society for Training and Development (ASTD) reports major skill gaps in the US. The 2013 ASTD report states that US organizations spent $\sim \$ 164.2$ billion on employee learning in $2012^{2}$. The US is facing an alarming high replacement need for STEM professionals ${ }^{3,4}$. For instance, the projected replacement rate in mathematical science is $29.5 \%$, in physics it is $28.5 \%$, in mechanical engineering it is $26 \%$, and in electrical engineering it is $23 \%$. It is estimated that during this decade, employers will need to hire about 2.5 million STEM workers, drawing largely from engineering and engineering technology programs that are known for equipping graduates with the tools to enter the workforce, for the first time, prepared ${ }^{5,6}$. This requires an innovative curriculum that involves hands-on opportunities for practical problem solving.

On the one hand, the pipeline for an educated future workforce is already in place. According to data from the Current Population Survey ${ }^{4}$, the share of the population aged 16 and over who have college degrees roughly doubled over the past three decades, as did the share of those with some college education. However, there is concern that the US is still not preparing a sufficient number of students, teachers, and professionals in STEM areas ${ }^{7-10}$. In a recent international assessment of 15-year-old students, the US ranked 28th in math literacy and 24th in science literacy. Moreover, the US ranks 20th among all nations in the proportion of 24-year-olds who earn degrees in natural science or engineering ${ }^{7}$.

With a growing emphasis on student learning outcomes and assessment, faculty and educators constantly seek ways to integrate theory and research in innovative course design methodologies ${ }^{11-15}$. Critics of engineering education argue that educational programs focus too much on the transmittal of information through static lecture-discussion formats and routine use of outdated laboratory exercises ${ }^{16,17}$. This educational approach often results in graduates who do not have a full range of employable skills, such as, the ability to: apply the knowledge skillfully to problems, communicate effectively, work as members of a team, and engage in lifelong learning. As a result, engineers and engineering technologists often enter the workforce inadequately prepared to adapt to the complex and ever-changing demands of the high-tech workplace $^{18}$. Research ${ }^{19-21}$ shows that active learning, learning that involves hands-on experience, significantly improves student comprehension and proficiency.

Programmable Logical Controller (PLC) is an integral part of nearly all today's industrial processes. A PLC is a digital computer used for automation of electromechanical processes and is designed for multiple inputs and output arrangements, extended temperature ranges, immunity to electrical noise, and resistance to vibration and impact. The most up-to-date PLCs have endless functionality, including programming using functional blocks, multitasking, and communication capabilities, and therefore are widely employed by the industrial sector. It is also very common that PLC systems are integrated with robotic solutions to enhance automation processes. As a result, the skills of newly employed industrial workers must include the knowledge of PLC, controls, and robotics. In addition, the knowledge of integration of all these 
tools in one efficient automated process suiting the requirements of modern industrial environment is crucial.

In this article we discuss the benefits of academia and industry collaboration, the structure of new industrial control and automation laboratory, state-of-the art PLC and Mechatronics stations integrated with FANUC robots, and resulting curriculum modifications.

\section{Industrial Automation Laboratories at the Other Universities}

At Virginia Tech, College of Engineering, the Robotics and Automation Laboratory ${ }^{22}$ is used as an instructional laboratory for undergraduate and graduate courses in industrial automation and robotics. It is also used as a research facility for projects with industry (e.g. guidance and control of driverless linked vehicles), NASA (e.g. automated fiber-composite structure manufacture), and NSF (e.g. automated path planning and passive assembly). The lab is equipped with: IBM 7545 industrial robot, two pairs of Merlin 6-axis robots, one pair with force sensing wrists, integrated assembly work cell, three CNC controlled milling machines and a CNC lathe, and stand-alone data acquisition and control systems.

Minnesota State University, Mankato, Department of Electrical and Computer Engineering and Technology (ECET), an industrial automation laboratory ${ }^{23}$ is established through a combination of funding from the Minnesota Center for Excellence in Manufacturing \& Engineering, a Minnesota State Colleges and Universities program, and a significant contribution through Rockwell Automation's education discount program. The automation equipment set up on lab benches includes: Rockwell Automation ControlLogix PLC 17-slot chassis, 1756-L60M03SE 3axes ControlLogix controller with SERCOS, Kinetix 6000 Servo Drive, 2094-AC05-MP5, X-Y stage and 2 servomotors, TL-A120P-BJ32-AA, Digital and Analog Input \& Output DC \& AC modules \& connector cables, EtherNet/IP network, ControlNet network \& DeviceNet network, PanelVIEW touch panel, Switch input and LED display panel, Photoelectric sensor, Fluke portable oscilloscope \& multi-meter.

At Lake Superior State University, School of Engineering \& Technology, the Robotics and Automation Laboratory ${ }^{24}$ is equipped with vision systems, sensors and rotary index tables, and a variety of software and PLCs. The robots are manufactured by Staubi and Fanuc. The Staubi work cell accommodates a rotary index table and a Bosch continuous palletizing conveyor system that is shared among four robots. The robots are equipped with tool changing systems, end-of-arm devices and vision systems, and are operated by means of PLCs using DeviceNet and VAL3 softwares. The Fanuc work cell includes an oval track which surrounds four Arcmates. A continuous conveyor system coordinates the activities among the robots, which are programmed by Karel software.

In the University of Pittsburgh, Swanson School of Engineering, the Automation and Robotics laboratory ${ }^{25}$ serves as a teaching and research lab, which includes Intelligent robotic systems, futuristic automated designer systems that accommodate customer interaction electronically at the design phase, computer aided design and manufacture of innovative medical devices and systems, integrated devices that require multi-disciplinary modeling and analyses tools, and integrated product designer systems which use dynamic data for product design configuration and optimization. The lab has received funding from the National Science Foundation, ALCOA, Inc., Mallinckrodt, Inc., Digital Equipment Corporation, Respironics, Inc., Children's Hospital of 
Pittsburgh, Ben Franklin Technology Center of Western Pennsylvania, NATO, General Electric, IBM, United Technologies Corporation, and the U.S. Army Research Labs.

In Eastern Illinois University, School of Technology, the Automation and Control Laboratory ${ }^{26}$ includes the required equipment for basic DC and AC theories, solid-state circuits and concepts, microcomputer interfacing and control, micro-controllers, data acquisition, and digital data communication. The lab facilities support a variety of courses including: Electrical Control Systems, Routing and Switching, Programmable Logic, Robots and Control Systems, Microcomputer Interfacing and Data Acquisition, Automation and Control Systems, and Automation Identification and Data Capture.

At Michigan State University, Department of Electrical and Computer Engineering, the Robotics and Automation Laboratory ${ }^{27}$ includes 2 PUMA 560 robot arms. Each arm is equipped with sixaxis force/torque sensor and a gripper, and mounted on Nomad XR4000 mobile platform. The mobile manipulators are equipped with wireless Ethernet, laser range finder, and CCD cameras. The lab also has a fleet of micro wall climbing robots, each equipped with infrared sensor, CCD camera, and radio communication link. In addition, a micro robotic system is developed which consists of a 3-DOF micro manipulator, a 3-DOF platform, and a 2-DOF micro force sensor installed on the micro manipulator. The sensor is capable of measuring contact force at the sub micro Newton scale. This system is equipped with a microscope and a CCD imaging system, and is controlled by a PC-based control system. The lab is also equipped with an atomic force microscope (AFM) based nano-robotic system, which is designed for imaging and manipulation of objects at the nanoscale.

\section{Michigan Tech and Nucor Collaboration}

Michigan Tech prepares the graduates with the skill sets which are up-to-date and relevant to the modern technologies widely employed by the modern industrial world. We strive to train our graduates on the most up-to-date laboratory equipment so they can implement their knowledge on the day one once employed. Michigan Tech collaborates with NUCOR Steel to update the currently outdated PLC laboratory with the state of the art equipment with the goal of providing our students with the best training solution possible. This collaboration will enable the opportunity to graduate students with the skills which are up-to-date and relevant to the current needs of industry striving to fulfill the engineering positions with highly qualified specialist. On the long run this collaboration will help to reduce assist the entire industrial sector with its workforce needs.

Michigan Tech is a public university committed to providing a quality education in engineering, science, business, technology, communication, and forestry. Fall 2014 total enrollment was 7,100 students, including 1,442 (20.6\%) graduate students. Over 65\% of Michigan Tech students are enrolled in engineering and technology programs. Cumulatively, the School of Technology (SOT) and College of Engineering (COE) granted 700 undergraduate degrees in 2012-13; 63\% of total first-major Michigan Tech undergraduate degrees. Twenty-two research centers and institutes support interdisciplinary research, partnerships with industry, and collaboration with community and informal education organizations. The SOT awards bachelor's degrees in Computer Network \& System Administration, Construction Management, Electrical and Computer Engineering Technology, Mechanical Engineering Technology, and Surveying Engineering - all degrees that require an understanding of robotics. Michigan Tech is rated 
highly for academics, career preparation, and quality of life in the Princeton Review's Best 379 Colleges 2015 Edition. Michigan Tech is ranked in the top tier of national universities according to the U.S. News \& World Report's "America's Best Colleges 2014." Employers, especially in the state of Michigan, have consistently relied on Michigan Tech to deliver experiential educational opportunities. That is why Michigan Tech students average five interviews before they graduate, and why, despite record levels of unemployment in Michigan over the past three years, Michigan Tech has maintained on average a 93\% job placement rate.

The Alliance for Computing, Information and Automation was established at Michigan Tech to provide a mechanism for fostering research and education collaboration among academic units with a strong focus on all things computing. The units that are members of the alliance are the Department of Electrical and Computer Engineering (ECE) in the College of Engineering, the Department of Computer Science (CS) in the College of Sciences and Arts, and the departments of Computer Network \& System Administration (CNSA) and Electrical Engineering Technology (EET) in the School of Technology. The Alliance has a non-departmental structure with an executive committee consisting of the heads of ECE, CS and the School of Technology. Each administrator serves as Director of the Alliance on a rotating basis. The existing departments maintain their current identities and autonomy.

A Curriculum Task Force was formed and a review of all curricula took place which resulted in the elimination of duplicate course offerings and restructuring of some existing courses to allow more flexibility for students to take courses that are not offered in their home departments. This review identified the need for a more robust offering of courses related to Programmable Logic Controllers (PLCs), which would serve the needs of students in ECE and EET, and students in other disciplines across campus. In particular, the ECE department wanted to expose students to more hand-on use of PLCs, and the EET department had been working on ways to upgrade and enhance its PLC labs. The communication channels and opportunities for joint discussions provided through the Alliance structure paved the way for successful discussions between the units and resulted in a successful funding proposal submitted to Nucor.

Nucor Corporation is a Fortune 150 company headquartered in Charlotte, NC, United States. It is the second largest steel producer in the United States, and the largest of the "mini-mill" steelmakers which use electric arc furnaces to melt scrap steel, as opposed to companies operating integrated steel works with blast furnaces. Nucor is North America's largest recycler of any material, recycling one ton of steel every two seconds. The company's total annual steelmaking capacity exceeds 27 million tons ${ }^{28}$. Nucor operates 23 scrap-based steel production mills $^{29}$. Nucor was among the first steel companies in the United States to use electric arc furnaces to melt recycled steel (primarily from junked automobiles). In 2007, Nucor recycled nearly 10 million cars in its production processes, the equivalent of one SUV every four seconds. The company's website maintains a running count of the tons of recycled steel used during the current calendar year. Currently, Nucor (in conjunction with two foreign-owned steel companies) operates a facility in Crawfordsville, Indiana that continuously casts sheet steel directly from molten steel without the need for heavy, expensive, and energy-consuming rollers. The process known as Castrip ${ }^{30}$, if successful, would allow an entire mill to be built in $1 / 6$ the space of a 'mini-mill' and at 1/10 the cost of a traditional integrated mill. They call this concept a 'micro- 
mill'. Also, Nucor has two pilot projects, one in Western Australia and one in Brazil, which are developing low-cost sources of iron for use in its mills.

\section{Control and Automation Curriculum and Laboratory at Michigan Tech}

Michigan Tech prepares the graduates with the skill sets which are up-to-date and relevant to the modern technologies widely employed by the modern industrial world. We strive to train our graduates on the most up-to-date laboratory equipment so they can implement their knowledge on the day one once employed. Michigan Tech collaborates with NUCOR Steel to update the currently outdated PLC laboratory with the state of the art equipment with the goal of providing our students with the best training solution possible. The EET program at Michigan Tech currently offers two PLC courses: EET 3373 Introduction to Programmable Controllers and EET 4373 Advanced Programmable Controllers. The ECE department offers EE3261 Control Systems and EE 4262 Digital and Non-linear Control. The EET courses have a significant lab component and stress hands-on use of PLC's, while ECE courses have more of a mathematical flavor and also include a lab experience. The new lab facility would allow EET 3373 and EET 4373 to be revised and enhanced to make the courses appropriate for both ECE and EET students. Students from both disciplines would benefit from using the most current PLC technology and would have the opportunity to interface the PLC's with a new and much expanded set of digital and analog devices that are used in industry. In addition, the new equipment will allow us to develop industry-relevant learning materials, and provide state-of theart knowledge and experience to students utilizing the facility. This knowledge and experience will result in a well-educated graduate with practical hands-on experience designing, configuring, and troubleshooting industrial control systems, with an obvious benefit to employers of these graduates.

\section{Newly Equipped Industrial Control and Automation Laboratory}

Generous gift of Nucor provided to Michigan Tech made it possible to equip the new Industrial Control and Automation Laboratory with state-of-the-art Programmable Logic Controllers and Mechatronics stations integrated with FANUC robots. The authors conducted significant research on the type of equipment, as well as vendors producing this equipment to ensure that newly equipment, laboratory would allow to teach skills which are relevant to the current needs of industry. Based on conducting research and feedback collected from the industry representatives it was decided to utilize Allen Bradley Control Logic 5000 PLC which is widely represented within the industrial sector. The selection of the vendor producing training equipment fell on Amatrol $\mathrm{Inc}^{31}$, the company which specializes in designing and manufacturing up-to-date and relevant for the industry needs training equipment. The industrial relevance of manufactured by Amatrol Inc. Training equipment comes from the companies approach during the design and development stage of a particular piece of equipment. Amatrol, Inc. continiousy survey industry firms on their needs in particular sectors of the knowledge base of newly employed graduates. When the gap in particular segments of knowledge is detected, the company immediately assembles a team of specialists consisting of several representatives from industry and academia. All members of the team share their perspective to the approach to developing the training equipment as well as accompanying curriculum. The presence of both academia and industry provides a perfect mix of knowledge and expertise resulting in the 
training equipment that teaches the required by the industry knowledge in easily adaptable by the academia model. After extensive research it was decided to equip the new industrial control and automation laboratory with eight portable PLC trainers and four Mechatronics stations, with one of the stations incorporated with FANUC industrial robots.

\section{Amatrol Equipment}

Modern industry has experienced a rapid proliferation of automated technology that has greatly improved production efficiency and output. At the center of this technology is the programmable logic control (PLC), meaning today's workforce must acquire skills in programming and operation of PLC systems that use a variety of basic and advanced program commands. The 990PAB53 Portable PLC Learning Syste ${ }^{29}$, shown in Figure 1 addresses this need by providing a comprehensive curriculum and application workstation that teaches modern PLC systems as they are used in the industry today. Students learn both basic and advanced applications using the powerful Allen Bradley CompactLogix 5300 PLC, a PanelView Plus terminal, and networks throughout the curriculum. The 990PAB53 System comes with a mobile carrying case, workstation mounting panel, master control relay circuit, Allen Bradley CompactLogix 5300 Programmable Controller, RS Linx and RS Logix 5000 software, a PanelView Plus terminal, an Ethernet Switch, I/O Simulator, five application circuits, student curriculum, instructor's assessment guide, and installation guide ${ }^{29}$. Learners will study industry relevant skills, including how to operate and program PLC systems for a wide range of real world applications.

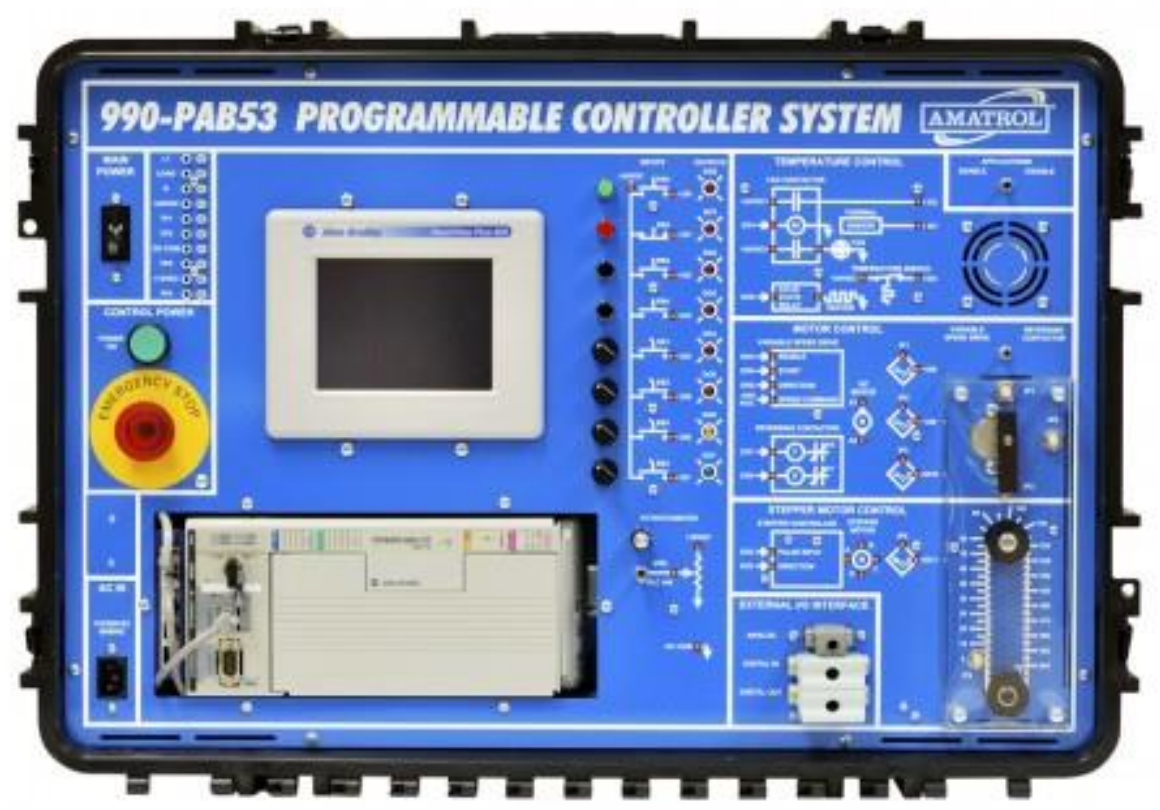

Figure 1: Amatrol 990PAB53 Portable PLC Learning System

The 990PAB53 Learning System enhances learning by featuring a wide array of real world applications to allow students to actually see their programs control real systems. In addition to a 
discrete I/O simulator with discrete switches and indicators, the 990PAB53 includes application circuits and components for thermostatic temperature control, analog temperature control, reversing constant speed motor control, variable speed motor control with feedback, and stepper motor homing and commissioning. These circuits include basic and advanced applications starting with discrete $\mathrm{I} / \mathrm{O}$ projects and extending to projects involving analog $\mathrm{I} / \mathrm{O}$. In addition to all the features mentioned above, the portable system has outstanding capabilities of fault insertion of software and hardware levels and features 35+ electrical faults. The fault insertion capability provides students with unique, real world like opportunity to troubleshoot the industrial equipment in academic settings.

Modern industry relies on highly complex production systems to produce high-quality economical products ${ }^{31,30}$. Mechatronics teaches the critical thinking skills required to effectively operate, program, and troubleshoot complex industrial production systems involving mechanical, electrical, electronics and software aspects. Amatrol's Mechatronics learning systems ${ }^{31}$ shown in Figure 2 teach students a broad array of job-ready skills in integrating technologies. Seven stations make up a complete, flexible manufacturing system. Each station is a small Mechatronics system in itself, with multiple integrated technologies that can be used as a stand alone or in various combinations, creating unlimited project capabilities.

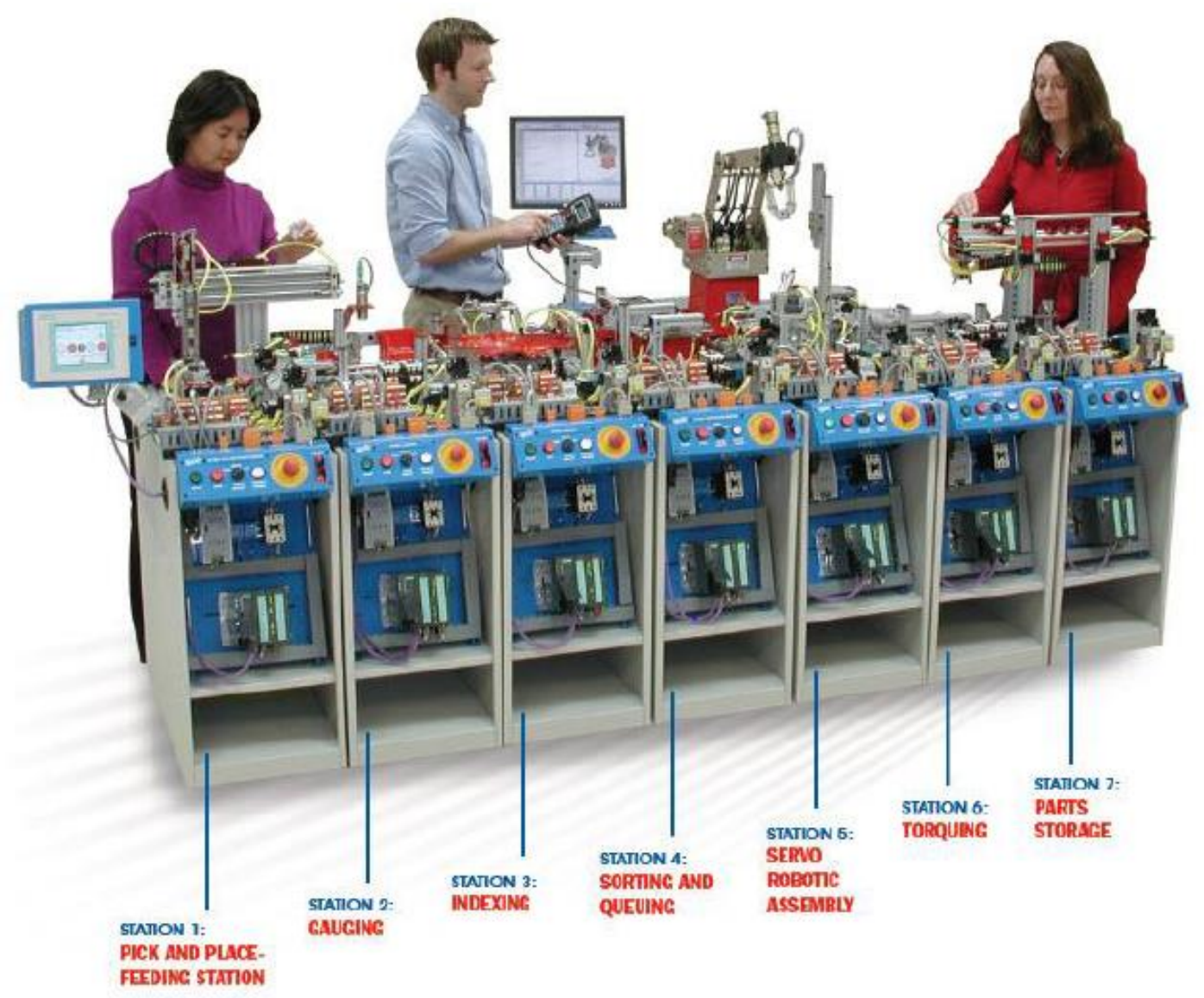

Figure 2: Amatrol's Mechatronics learning systems 
These seven stations are:

1. Pick and Place Feeding Station

2. Gauging

3. Indexing

4. Sorting and Queuing

5. Servo Robotic Assembly

6. Torquing

7. Parts Storage

Amatrol Mechatroniocs Learning Sytem ${ }^{31}$ uses off-the -shelf industry standard components typical of what graduates will see in the industry. Recreating the industrial environment in the classroom settings helps make students job-ready by building skills using equipment they will find in the workforse. This versatile learning system teaches a very broad set of subjects such as variable speed motor control, ultrasonic measurement, constant speed motors, electrical sensors, stepper motors, fiber optics, DC motors and robotics.

In addition to eight portable PLC trainers the laboratory has also been equipped with four Mechatronics stations: Pick and Place, Feeding, Sorting and Queuing, and Servo Robotic Assembly. The authors are currently investigating the opportunity of securing additional funds to add three more stations and complete the system.

Amatrol's unmatched multimedia ${ }^{31}$ utilizes text, audio, and stunning 3D animations that engage learners in both theoretical knowledge and hands on skills. This thorough, exceptionally detailed curriculum $^{31}$ is built to begin with the basics and steadily advance to more complex concepts and skills. Through partnerships with key industry leaders and leading edge educators, Amatrol developed the right balance of knowledge and applied skills needed to train learners to work in their chosen field.

\section{Faculty Training at Amatrol Facility}

The two-week training was offered by Amatrol $\mathrm{Inc}^{31}$ to the faculty members involved in the laboratory and curriculum development, and consisted of one week (36 hours) of Portable PLC Learning System based on Allen-Bradley ControlLogix $5300^{29}$, and one week (36 hours) of Mechatronics Learning System ${ }^{33}$.

The Portable PLC Learning System 36-hour training ${ }^{32}$ provides a comprehensive curriculum and application workstation including a mobile carrying case, workstation mounting panel, master control relay circuit, Allen-Bradley CompactLogix 5300 Programmable Controller, RS Linx and RS Logix 5000 software, a PanelView Plus terminal, an Ethernet Switch, discrete and analog I/O Simulator, student curriculum, instructor's assessment guide, and installation guide. It also includes five application circuits, namely, (1) thermostatic temperature control, (2) analog temperature control, (3) reversing constant-speed motor control, 4) variable speed motor control with feedback, and (5) stepper motor homing and commissioning. These application circuits cover a wide range of industry-relevant skills to operate and program PLC systems for real industrial applications. The multimedia curriculum utilizes text, audio, and 3D animations that engages learners in a balance of theoretical knowledge and hands-on skills. A sample copy of 
this course's Student Reference Guide is included with the learning system. Sourced from the multimedia curriculum, the Student Reference Guide takes the entire series' technical content contained in the learning objectives.

The Mechatronics Learning System 36-hour training ${ }^{33}$ provides a broad array of real-world Mechatronics skills that cover various applications across a balance of mechanical, electrical, electronics, fluid power and software, which are applicable in different industries such as automotive, pharmaceutical, chemical, and etc. The training is focused around seven stations, that make up a complete, flexible manufacturing system, namely, (1) pick and place feeding, (2) gauging, (3) orientation processing, (4) sorting and buffering, (5) servo robotic assembly, (6) torque assembly, and (7) inventory storage. Each station is an individual Mechatronics system with multiple integrated technologies that teach operation, sequencing and programming skills. In order to be used as a stand-alone individual workstation, each station can be easily moved apart by releasing two quick connects and one plug-in cable. Stations can also be mixed and matched in various combinations, enabling instructors to build and change the system as budgets allow or needs change. The full-size seven-station Mechatronics system includes eight types of electronic sensors, three types of electrical motors, four types of pneumatic actuators, and 20 different mechanical power transmission components. The curriculum covers several automation topics such as control system concepts, Mechatronics safety, programmable controllers, PLC programming language, PLC program analysis, motor control basics, program development, timer instructions, time-driven sequencing, and etc. The Mechatronics training includes an online teaching tool, with a comprehensive curriculum in print-based and either multimedia or eBook formats.

\section{Conclusion}

Academic programs in the School of Technology at Michigan Tech are designed to prepare technical and/or management-oriented professionals for employment in industry, education, government, and business. The EET program in the SoT is constantly revamping the curriculum to meet the expectations of industry by supplying qualified technicians and technologists who have extensive hands-on experience. To further enhance and make the curriculum model more flexible, all programs across in the SoT are developing and offering online courses in multiple disciplines. In this article we discuss the benefits of academia and industry collaboration, the structure of new industrial control and automation laboratory, state-of-the art PLC and Mechatronics stations integrated with FANUC robots, and resulting curriculum modifications.

\section{References:}

1. ManpowerGroup : Annual Talent Shortage Survey (http://www.manpowergroup.com/talent-shortageexplorer/\#.VAnGjvmwJ8E)

2. American Society for Training and Development Report (http://www.astd.org/Professional-Resources/State-OfThe-Industry-Report )

3. F.P. Deek, F.P., Kimmel, H., \& McHugh, J., "Pedagogical changes in the delivery of the first course in computer science: Problem solving, then programming ”, Journal of Engineering Education, 87, 3, pp. 313-320, July 1998.

4. Replacement needs in 2008-18, 2008 National Employment Matrix title and code, Bureau of Labor Statistics http://www.bls.gov/emp/ep table 110.htm 
5. D.Liming and M.Wolf, "Job Outlook by Education 2006-16", Office of Occupational Statistics and Employment Projections, BLS

6. N. Terrell, the Office of Occupational Statistics and Employment Projections, "STEM Occupations", Occupational Outlook Quarterly 2007, BLS

7. Occupational Outlook Handbook www.bls.gov/oco.

8. J. Kuenzi, C.Matthew, and B. Mangan, "Science, Technology, Engineering, and Mathematics (STEM) Education Issues and Legislative Options", CRS Report for Congress, 2006.

9. Bonvillian, W. B. "Science at a crossroads", The Federation of American Societies for Experimental Biology Journal, 16, 915-921, 2002.

10. Gonzales, P., Guzmán, J. C., Partelow, L., Pahlke, E., Jocelyn, L., Kastberg, D., \& Williams, T., "Highlights from the Trends in International Mathematics and Science Study (TIMSS)", Washington, DC: U.S. Department of Education, National Center for Education Statistics, 2003.

11. Bowden J.A., "Curriculum development for conceptual change learning: A phenomenographic pedagogy", Occasional Paper 90.3, ERADU, RMIT University, Melbourne, Australia, 1989.

12. Diamond R.M., " Designing and Assessing Courses and Curricula: A Practical Guide " San Francisco, CA: Jossey-Bass, 1997.

13. Fink L.D., "Creating Significant Learning Experiences: An Integrated Approach to Designing College Courses", San Francisco, CA: Jossey-Bass, 2003

14. Saroyan A., Amundsen C., "Rethinking teaching in higher education: From a course design workshop to a faculty development framework", Sterling, VA, Stylus Publishing, LLC,2004.

15. Toohey S., "Designing courses in Higher Education", Buckingham, UK: SRHE and Open University Press, 1999.

16. F.P. Deek, F.P., Kimmel, H., \& McHugh, J., "Pedagogical changes in the delivery of the first course in computer science: Problem solving then programming”, Journal of Engineering Education, 87, 3, pp. 313-320, July 1998.

17. Meier, R.L., Williams, M.R., and Humphreys, M.A., "Refocusing our efforts: assessing non-technical competency gaps", Journal of Engineering Education, 89, 3, pp. 377-385. 2000.

18. Massa N.M., Masciadrelli G.J, Mullett G.J., " Re-Engineering Technician Education For The New Millennium", Proceedings of ASEE AC 2005-504.

19. Bransford, J. D., Donovan, M. S., Pellegrino, J. W., (Eds.), How People Learn, Washington, DC: National Academy Press, 1999.

20. Keeton, M. T., Sheckley, B. G., \& Griggs, J. K.," Effectiveness and Efficiency in Higher Education for Adults", The Council for Adult and Experiential Learning (CAEL), Chicago, 2002.

21. Prince, M., "Does Active Learning Work? A Review of the Research", Journal of Engineering Education, pp. 223-231, July 2004.

22. Robotics and Automation Laboratory at VirginiaTech: http://www.ise.vt.edu/ResearchFacilities/Labs/LabPages/RA_lab.html

23. Gale Allen, "New Industrial Automation Laboratory \& Courses ECET Technology Program Advancement", Proceedings of the Spring 2007 American Society for Engineering Education Illinois-Indiana Section Conference, Paper \#16: https://mavdisk.mnsu.edu/alleng/publications/automation11.pdf

24. Robotics and Automation Laboratory at Lake Superior State University: http://www.lssu.edu/eng/robotics_automation.php

25. Automation and Robotics Laboratory at Swanson School of Engineering: http://www.engineering.pitt.edu/Industrial/Research/Automation_and_Robotics_Laboratory/

26. Automation and Control Laboratory at Eastern Illinois University: http://www.eiu.edu/ tech/current_tech_lab_automation_control.php

27. Robotics and Automation Laboratory at Michigan State University: http://www.egr.msu.edu/ralab/Pages/Overview.htm

28 Steel Procurement Nucor Corporation: http://www.nucortrading.com/nucor.html

29. Nucor investor Relations. Annual Report 2013: http://www.nucor.com/investor/

30. Castrip: http://www.castrip.com/

31. Amatrol Inc. Website: http://www.amatrol.com/

32. Amatrol Inc. Website, Products, Portable PLC Learning System (Allen-Bradley ControlLogix 5300) - 990PAB53: http://www.amatrol.com/coursepage/pab53/

33. Amatrol Inc., Programs, Mechatronics: http://www.amatrol.com/program/mechatronics-3 / 